\title{
Research on electrical strain gages and experimental stress analysis: Case study for a full wheatstone bridge
}

\section{Gürkan İrsel ${ }^{1 * *}$}

Trakya University, Engineering Faculty, Department of Mechanical Eng., Edirne, Turkey, gurkanirsel@ @rakya.edu.tr,

https://orcid.org/0000-0003-0828-6560

\begin{tabular}{|c|c|}
\hline ARTICLE INFO & ABSTRACT \\
\hline $\begin{array}{l}\text { Received } 17 \text { October } 2021 \\
\text { Received in revised form } 26 \\
\text { October } 2021 \\
\text { Accepted } 7 \text { November } 2021 \\
\text { Available online } 31 \text { December } 2021 \\
\text { Keywords: }\end{array}$ & $\begin{array}{l}\text { This study investigated electrical strain gage technology, which is widely used in experimental stress } \\
\text { measurement, on an application. Strain gages are used to precisely measure strain directly in a system. This } \\
\text { method is carried out to verify the numerical and analytical calculations performed or to record the strain } \\
\text { data generated during the active duty of a system and to investigate the fatigue damage. In particular, } \\
\text { verifying numerical calculations in the strength-material recovery optimizations of mass-produced systems } \\
\text { contributes to the development of the system. In this study, strain measurement using strain gage and strain } \\
\text { measurement technology is presented on an application. Information was given about strain gages. A full } \\
\text { bridge wheatstone bridge consisting of } 4 \text { linear gages was created on a prototype. The system was tested } \\
\text { with a load cell validation. Structural finite element analysis of the prototype and analytical calculation of } \\
\text { the fullbridge strain gage connection were performed. The results showed that the measurement with the } \\
\text { strain gauge differed } 1.20 \% \text { and } 1.40 \% \text { from the analytical and numerical results, respectively. Thus, } \\
\text { precision strain measurement technology was successfully presented in engineering systems. }\end{array}$ \\
\hline
\end{tabular}

Doi: 10.24012/dumf.1051434

* Corresponding author

\section{Introduction}

Strain gages are used to measure the strain on an object with high measurement accuracy and small dimensions. Strain gages were invented by Edward E. Simmons and Arthur C. Ruge in 1938 [1]. They are used successfully in airplanes, especially in wing and landing gear, in heavy equipments, especially in chassis and gears, bridges, cranes, ships, automobiles, constructions etc. where stress measurement is important. Strain gages are electrical sensors. When a displacement occurs on the strain gauge, there is a change in its electrical resistance and with this change the amount of strain is measured. Stress value is obtained by associating this strain value with material properties. Today, there are gages developed for different materials and different applications. The use of strain measurement has increased in obtaining more durable lighter structures, in verifying the theoretical strength models of objects with complex geometry, in examining products in field tests and in revealing safety conditions. Strain measurement with strain gauges is carried out with special amplifiers (data acquisition system). This measurement requires many interrelated components and application expertise, from the selection and positioning of the strain gages to the visualization of the measurement with software.

There are special strain gauges that are welded and screwed to the surface, which are used for long-term stress measurement, but the common one is to stick the strain gauges to the surface to be measured strain. Strain gauges are commercially available in linear, 0/45/90, 0/60/120, T $(0 / 90)$, shear format. Stress measurement in special systems can be done easily by using these traditional models together. There are many types and sizes of gauges and strain gauges are selected from the catalogues for application. The data acquisition system is selected depending on how many gauges will be collected simultaneously. Special software is also used to display and save strain data from the data acquisition system [2]. Connections of the strain gauges and measurement calculations are also a specialty. Strain measurement configurations are quarter, half and full bridges.

There are some studies where strain gauges are used for experimental stress measurement. Celik et al. [3] designed a crane that could be mounted on a tractor. After producing this crane, they attached strain gages to certain locations. 
They measured the strain at these locations with the HBM 840A using a 0/45/90 degree rosette and determined that numerical calculations and strain gauge measurements were compatible. Lisle et al. [4] measured the tension in the teeth of internal gears using a strain gauge with a wheatstone bridge connection and compared them with the numerical results. In Whetstone bridge, compensation was performed to eliminate the temperature effects. This demonstrated that the stress measurement was performed accurately on complex surfaces such as gears [5]. Moustabchir et al. [6] developed and validated an experimental technique using strain gauges for the determination of strain distribution in pressurized cylindrical tanks. It has been determined that the verification of numerical calculations with strain gauge measurements will reduce the need for experimentation. Yürdem et al. [7] performed a stress analysis on a plow using a strain gauge. In their study, they used linear gagues and analyzed the system by converting stress measurements in different axes to von Mises stress. They found that the obtained results were compatible with the numerical solutions [8]. Ma et al. [9] measured stress with a strain gauge in a bridge maintenance and test vehicle. The tension in the system was recorded at the time of operation by sticking the gage at a distance of $20 \mathrm{~mm}$ from the welded area. Using this stress data, the fatigue calculation of the system was also performed. Patil et al. [10]carried out the experimental testing and analysis of the helical gear using thegear dynamic stress test rig. Stress measurements were performed on the gears with a strain gauge. Experimental analysis was validated by finite element contact analysis. Gao et al. [11] successfully measured the stress on the pipe surface with a strain gauge in the bending test of a pressure pipe. Lisle et al. [12] measured the stress at the root of the tooth using a strain gauge. They used these measurement results to validate numerical and analytical solutions. They placed rosettes at three different locations and measured for different gear calculation methods. They found that the numerical and analytical results were consistent with the strain gauge results. They found that validation of numerical calculations was an effective scientific method to reduce experimental requirements for gears in the future. Almeida et al. [13] developed strain gauge-based ring sensors to measure the dynamic forces coming into the system in wind tunnel testing. They created a full bridge wheatstone bridge circuit in these rings. Thus, they improved the aerodynamic structure by precisely measuring the stress in the system. Yunjiang Lou et al. [14] performed strain gauge measurement and topology optimization studies in their study. Wheatstone bridge was used in the measurement. In 1843, British physicist Sir Charles Wheatstone invented a bridge circuit to measure electrical resistances. In this bridge circuit, known as the Wheatstone bridge circuit, unknown resistors are compared with well-defined resistors. The Wheatstone bridge is well suited for measuring small changes in a resistor and is therefore used to measure the change in resistance in a strain gauge (SG) [1][15]. Studies with detailed presentations on strain measurement with strain gauge are limited. This study aimed to eliminate these deficiencies both scientifically and industrially.

The aim of this study is to present the whole measurement process with strain gauge, to create a full-bridge wheatstone bridge on an application, to perform the stress measurement in the system experimentally, and to demonstrate the applicability of this method in scientific and industrial studies with today's technology. Measurements were made with strain gauges in a circular hollow steel body. Measurement values were compared with numerical and analytical calculations.

\section{Strain Gages Technology}

The gauges consist of carrier material (a), measuring grid (b) and connections (c) (Fig. 1). The strain value is calculated by precise measurement of the strain-related resistance change in the measuring section. The deformation is $\Delta \mathrm{L}: \mathrm{L}_{0}-\mathrm{L}_{1}$, The strain is $(\varepsilon)=\Delta \mathrm{L} / \mathrm{L}_{0}$. The stress $(\sigma)$ calculation can be made in linear elastic materials by the strain value and the elastic modulus of the material. Hooke's law in linear materials is calculated with the formula $\sigma=$ E.E. Stress can be measured bu using strain gages for ductile and brittle materials up to the limit of elasticity specified in the typical tensile tests seen in Fig. 2.

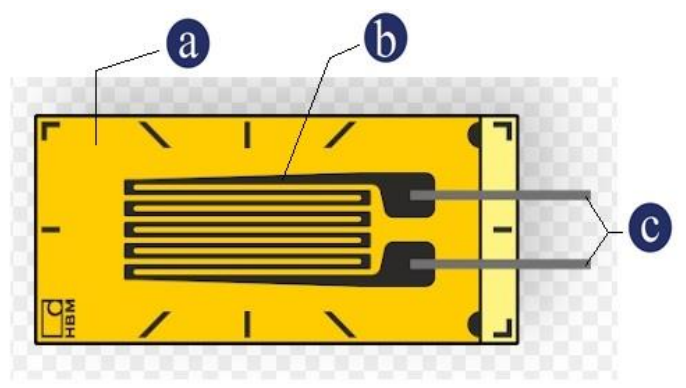

Figure 1. Linear strain gauge.

Strain gauges are electrical sensors. The change in resistance in strain gauges is precisely measured with a wheatstone bridge. Depending on the measurement requirement and precision, one or more strain gauges are used at the measuring point. Quarter bridge using 1 linear gage, half bridge using 2 linear gages, and wheatstone bridge using 4 linear gages are called full bridges. In fact, the circuit used for measurement is always complete. There are four resistors in the system. Non-variable resistors are complemented by fixed resistors. Quarter bridge, half bridge and full bridge configurations are shown in Fig. 3. For example, there are special sockets with developed electronics for quarter-bridge measurement. The connections of these sockets are made according to the data sheet of the brand (Fig. 4). 

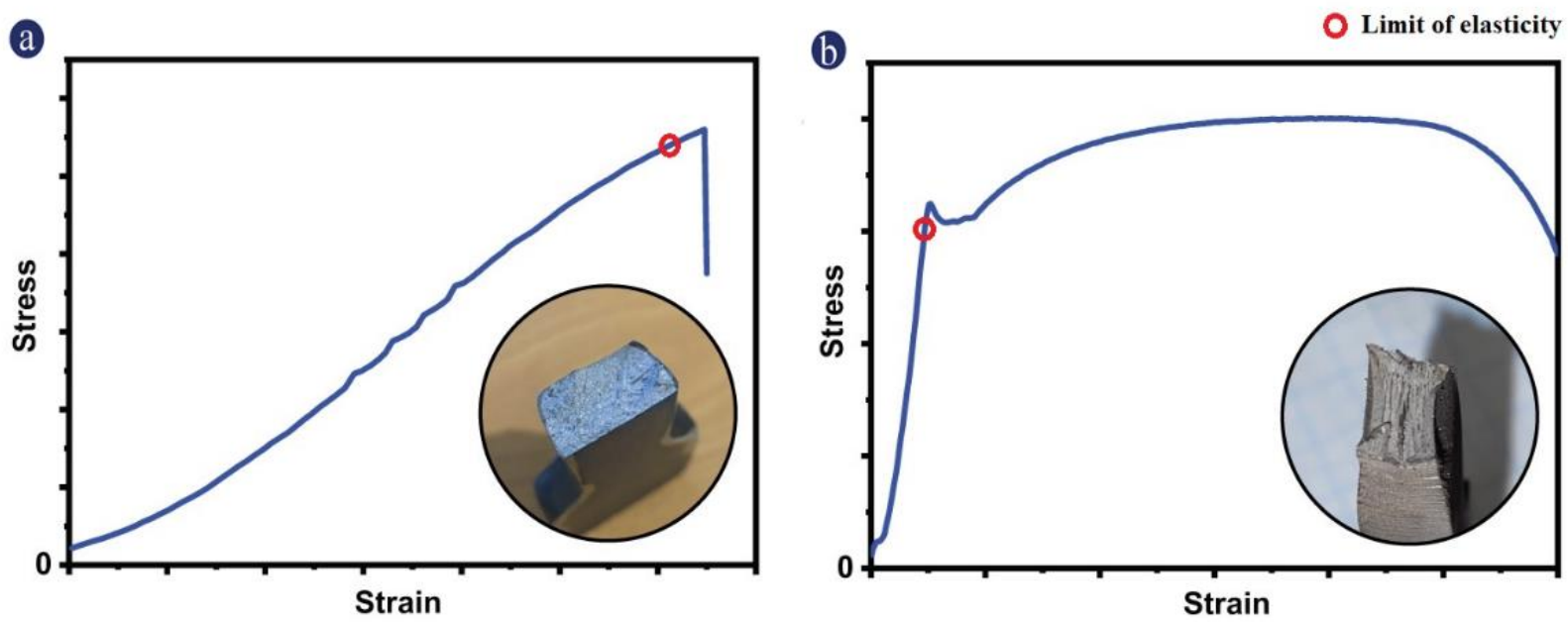

Figure 2. Steel stress-strain a) Characteristic of a brittle material b) Characteristic of a ductile material.
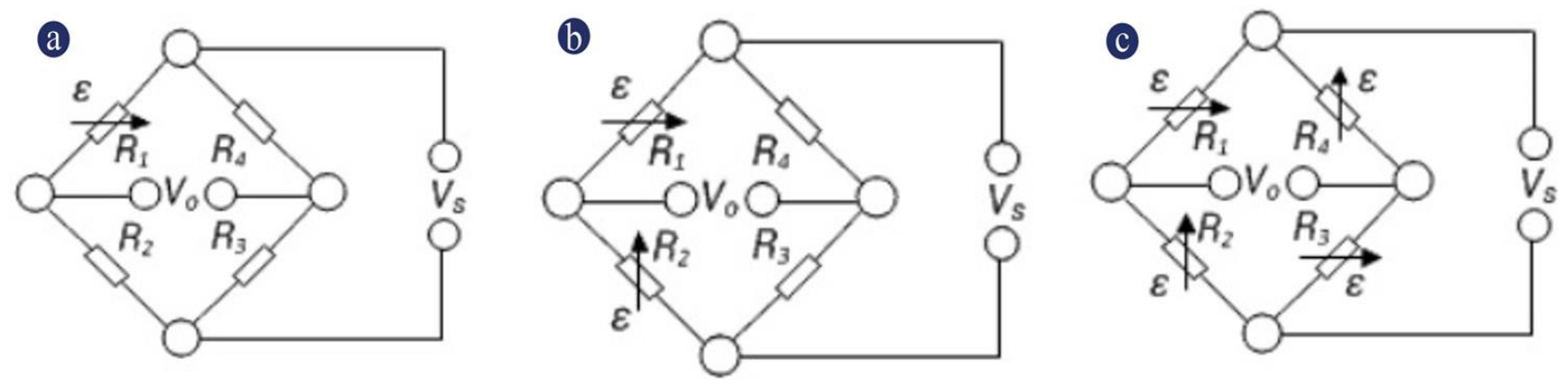

Figure 3. Wheatstone bridge circuits a) quarter bridge, b) half bridge, c) full bridge.

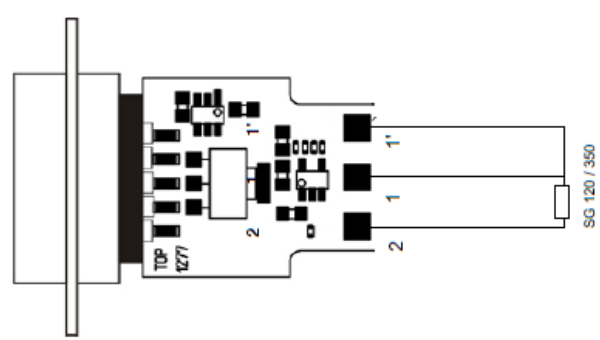

Figure 4. Example of a quarter bridge measuring adapter.

In this study, Full bridge configuration is discussed. Data acquisition system connection diagram of full bridge wheatstone bridge is shown in Fig. 5. In order to avoid confusion, the amplifier connection was made using a special colored signal cable. When a force is applied to a system to which strain gauges are attached, the change in resistance values on all 4 gages can be precisely measured with this system. In this connection consisting of 4 gages, gages 1 and 3 are positioned in the direction of force, and gages 2 and 4 are positioned at an angle of 90 degrees to the force direction. Strain in the wheatstone bridge seen in Fig. 5 is calculated with equations 1, 2 and 3. In equation
2, $\varepsilon_{2}=\varepsilon_{1} \times v$ because the gage number 2 is 90 degrees perpendicular to the force direction. $v$ poisson's ratio is 0.3 .

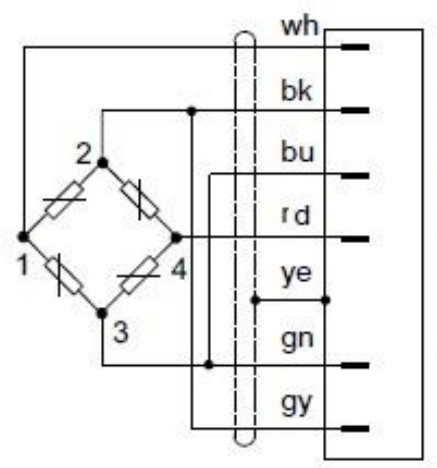

Measurement signal (+) Excitation (-) Excitation (+) Measurement signal (-)

Cable shield Sense lead $(+)$ Sense lead (-)

Figure 5. Wheatstone bridge data acquisition system connection diagram.

$$
\frac{V_{0}}{V_{s}}=\frac{k}{4}\left(\varepsilon_{1}-\varepsilon_{2}+-\varepsilon_{4}\right)
$$




$$
\begin{aligned}
& \left.\frac{V_{0}}{V_{s}}=\frac{k}{4}\left[\varepsilon_{1}-\left(-v \varepsilon_{1}\right)+\varepsilon_{3}\right)\right] \\
& \varepsilon=\varepsilon_{n}=\frac{1}{2(1+V)} \times \frac{4}{k} \times \frac{V_{0}}{V_{s}}
\end{aligned}
$$

\section{Experimental study}

In this study, a circular part was modeled with CATIA for measurement with a wheatstone bridge. This steel piece with an outer diameter of $100 \mathrm{~mm}$ and an inner diameter of $80 \mathrm{~mm}$ and a height of $80 \mathrm{~mm}$ was produced. A full bridge wheatstone bridge was designed using 4 linear gages (Figure 6). Gages 1 and 3 were marked in such a way that the gages 2 and 4 were 90 angled in the direction of force and the gages were precisely positioned.

Gages 1 and 2 are shown in the Fig. 6. Gages 3 and 4 are located at the back symmetrically. The cable connection of the system is presented in Fig. 5. For the steel material, linear gage HBM-LY61-6/350A, (Universal SG for stress analysis) strain gauge series $\mathrm{Y}$ was selected. The characteristics of this linear gage are: $\mathrm{k}: 2.01$ (The $\mathrm{k}$ Factor is the strain sensitivity of a strain gauge, $\mathrm{k}$ is the proportionality factor between the relative change in resistance $\Delta \mathrm{R} / \mathrm{R} 0$ and the strain to be measured with $\varepsilon$ ). The transverse sensitivity rate of this gage is $0.3 \%$. (The transverse sensitivity is the ratio of the sensitivity of a strain gauge transverse to the measuring grid direction to its sensitivity in the measuring grid direction). Measuring grid material of gage is constantan, carrier foil: polyimide. Temperature response: ferrite steel (10.8 ppm/K), Nominal resistance: $350 \mathrm{ohms}$, measuring grid length: $6 \mathrm{~mm}$. HBM -3133.0034 PVC-insulated ribbon cable was used for the amplifier connection with the Wheatstone bridge. This special cable consists of 6 leads, cross section per lead: $0.14 \mathrm{~mm}^{2}$, resistance: $0.131 \mathrm{Ohm} / \mathrm{m}$, thermal resistance of the cable is $-10^{\circ} \mathrm{C}$ to $+70^{\circ} \mathrm{C}$. Solder terminal was used for internal connection of strain gauge wheatstone bridge. The surfaces to be bonded to the gage were created with 100 and 330 grid sandpapers, respectively, with a roughness of approximately $6 \mu \mathrm{m}$. The surface was cleaned with pomades and necessary tools. The gage was moved to the desired position with a special tape. The gages were fixed with HBM Z70 adhesive. In this bonding process, pressure was applied on the gage with a finger for about 2 minutes. Teflon film layer was used to prevent the finger from sticking. Whether the gages adhered to the surface properly or not was tested with a special conveyor belt. Resistance was measured with an multimeter on the gage. Thus, it was checked whether there was any damage to the gages or an unexpected resistance value. The connections of the gages were made in accordance with the scheme and cable colors indicated in Fig. 4. It was prepared for measurement with a sufficient length of 1-3133.0034 HBM brand cable socket connection (Fig. 6) and connected to the Quantum HBM MX840B data collection device. A compression load cell with equal HSC-V 60t model calibration was used to instantly measure the force applied to this Annular application piece. This load cell is connected to the HBM quantum MX840B device with the E-MDL-DAC ECI analog board. With the CatmanEasy software compatible with the HBM MX840B data acquisition system, both the wheatstone bridge strain value and the force were simultaneously measured and recorded. The application ring and gage positions are shown in Fig 6.

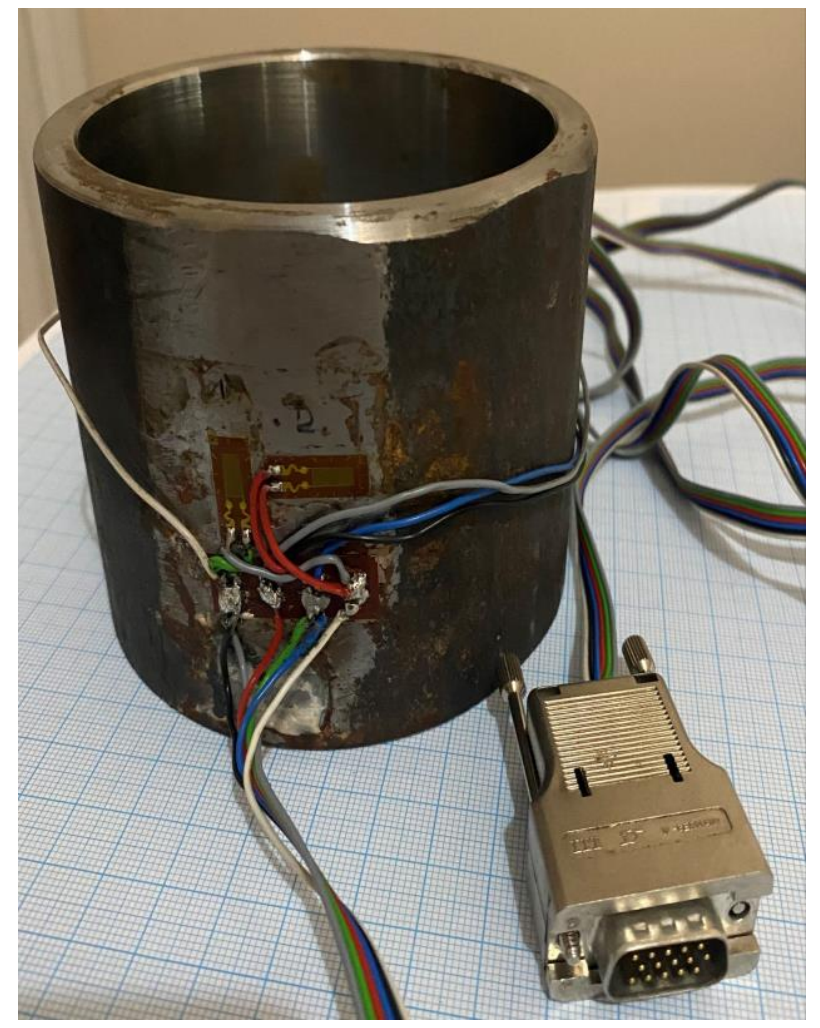

Figure 6. Wheatstone bridge implementation piece.

A load was applied to the application piece with a 30-ton compression device and an ALSA brand 30t compression tester at a compression speed of $1 \mathrm{~mm} / \mathrm{min}$ (Fig. 7). The load value and instantaneous stress value were recorded. Similar to Fig. 8, variable loading was applied to the piece, on which wheatstone bridge was applied, with the INSTRON 8501 device with a load capacity of $50 \mathrm{kN}$, and the stress and force values were recorded. 


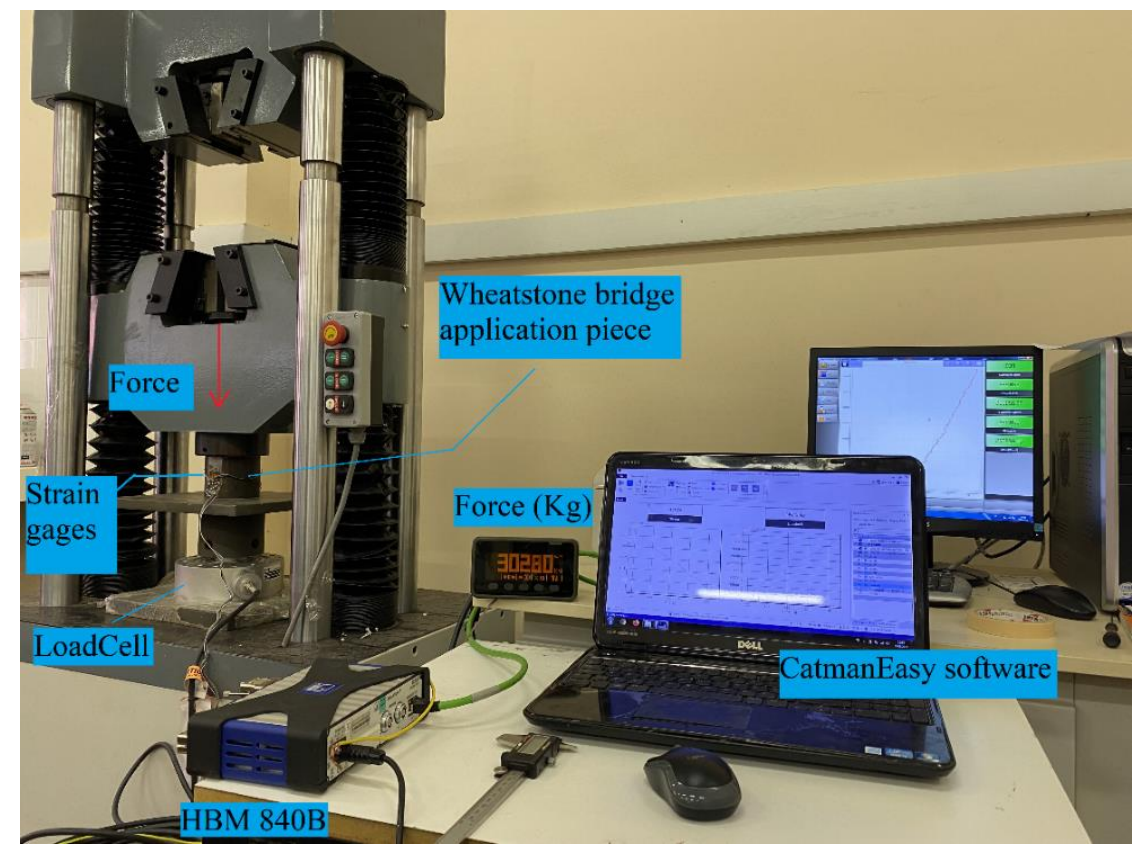

Figure 7. Force-strain measurement at 30 tons load.

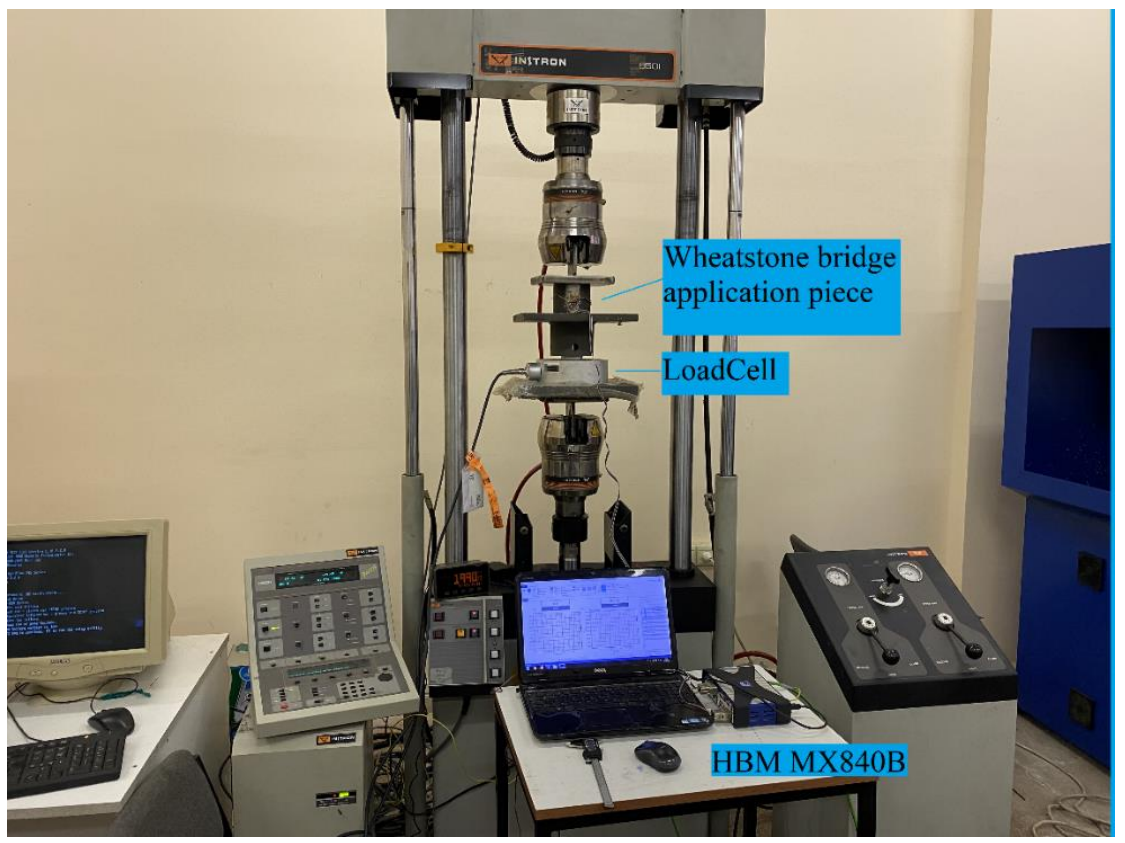

Figure 8. Force-strain measurement under variable loading.

\section{Results and discussion}

In this study, the details of the experimental stress analysis performed with a full wheatstone bridge created with strain gages are presented. Experiments of this application were carried out successfully. Half-bridge and quarter-bridge circuits are frequently used due to their ease of connection and less gage requirement [16]. However, a full-bridge circuit is the most suitable configuration for strain gauges. It provides the highest sensitivity and the least error component, and since the full bridge produces the highest output, it is least affected by electrical noise [17]. For these reasons, a full bridge should be used whenever possible. The resistance of the gauges adhered to the system was measured with an multimeter and their suitability for strain measurement was determined. Cable checks were carried out. As a result of the experiments carried out in the laboratory, force-time (Fig. 9) force-strain graphs were obtained for 30 tons of loading (Fig. 10). These graphs are simultaneous. 


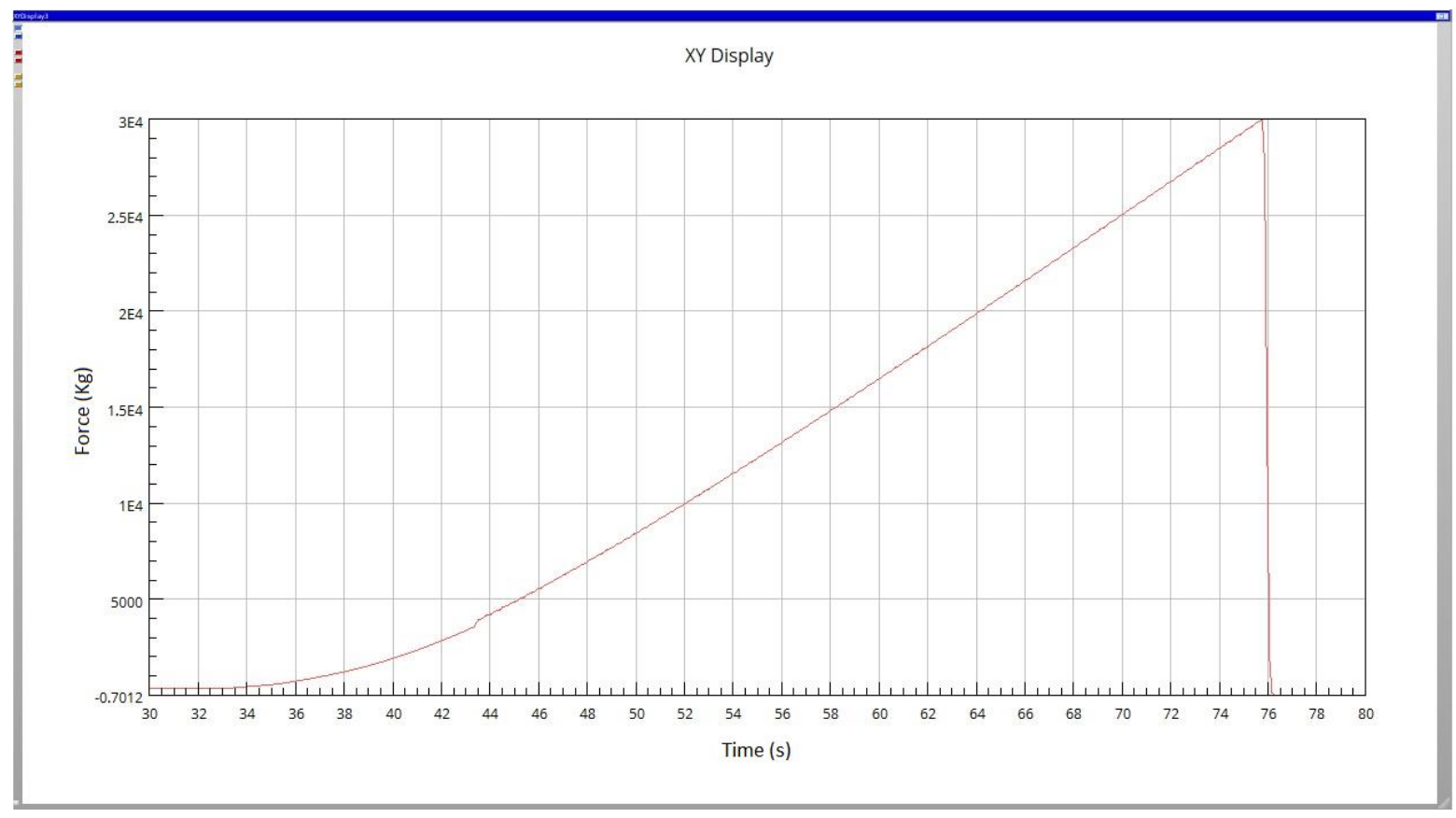

Figure 9. Force- time graph.

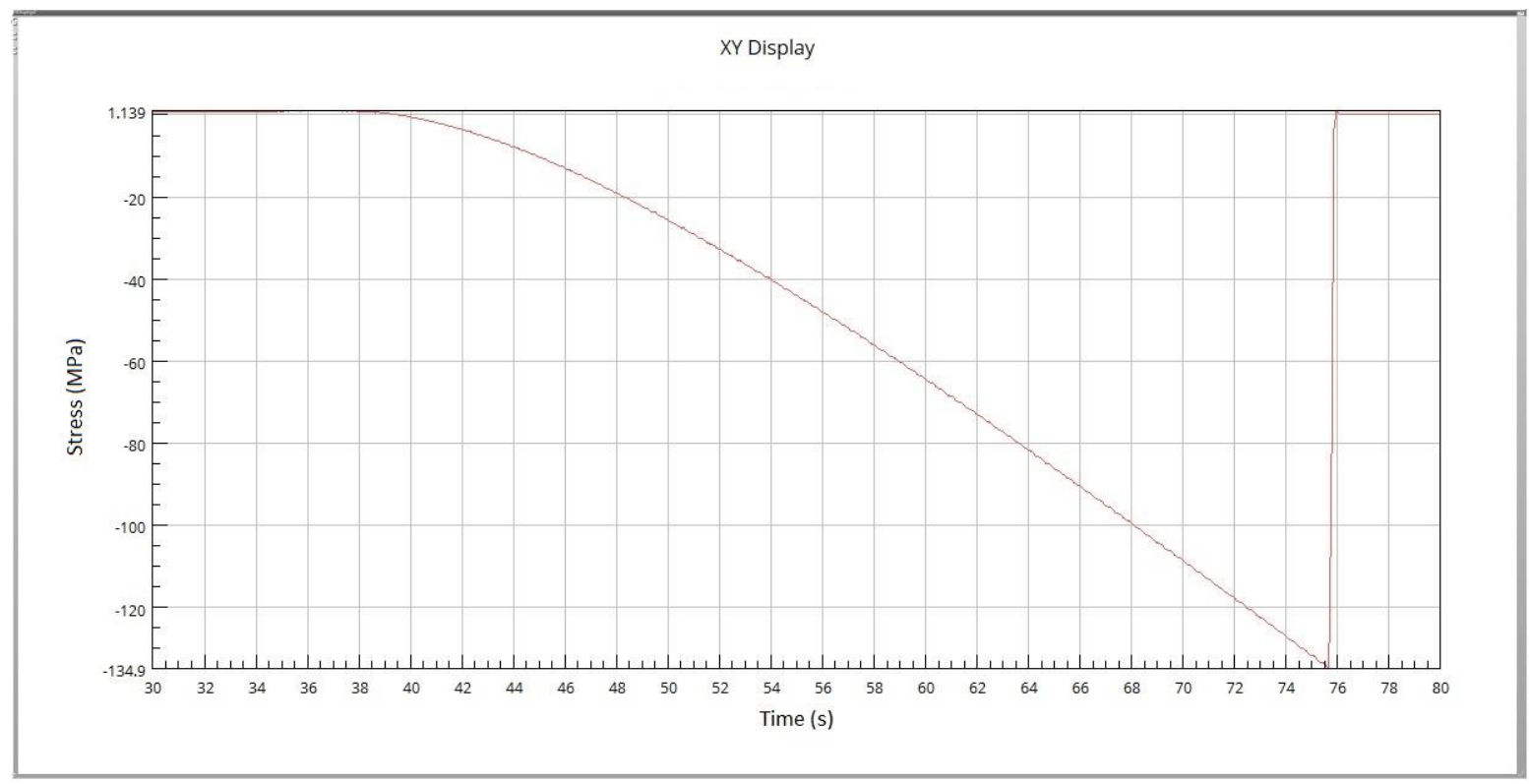

Figure 10. Wheatstone bridge Stress- time graph.

Stress measurement was carried out stepwise by keeping the application piece with Wheatstone bridge connection by increasing $5-50 \mathrm{kN}$ and $5 \mathrm{kN}$ increments for certain periods of time. Strain and stress values of this measurement are shown in Fig. 11-12. A strain of 22.95 $\mathrm{MPa}$ was measured for $50 \mathrm{kN}$. The stress measurement steps shown in Fig. 12 show the continuity and stability of the stress measurement [18]. These two graphs are created simultaneously. In the finite element analysis solution performed for the application part for a load of $50 \mathrm{kN}$, the strain at the strain gauge position was obtained as 22.624 $\mathrm{MPa}$ (Fig. 13) [2]. This numerical result is very close to the measured stress value. Stress values measured with numerical results are $98.6 \%$ compatible. 


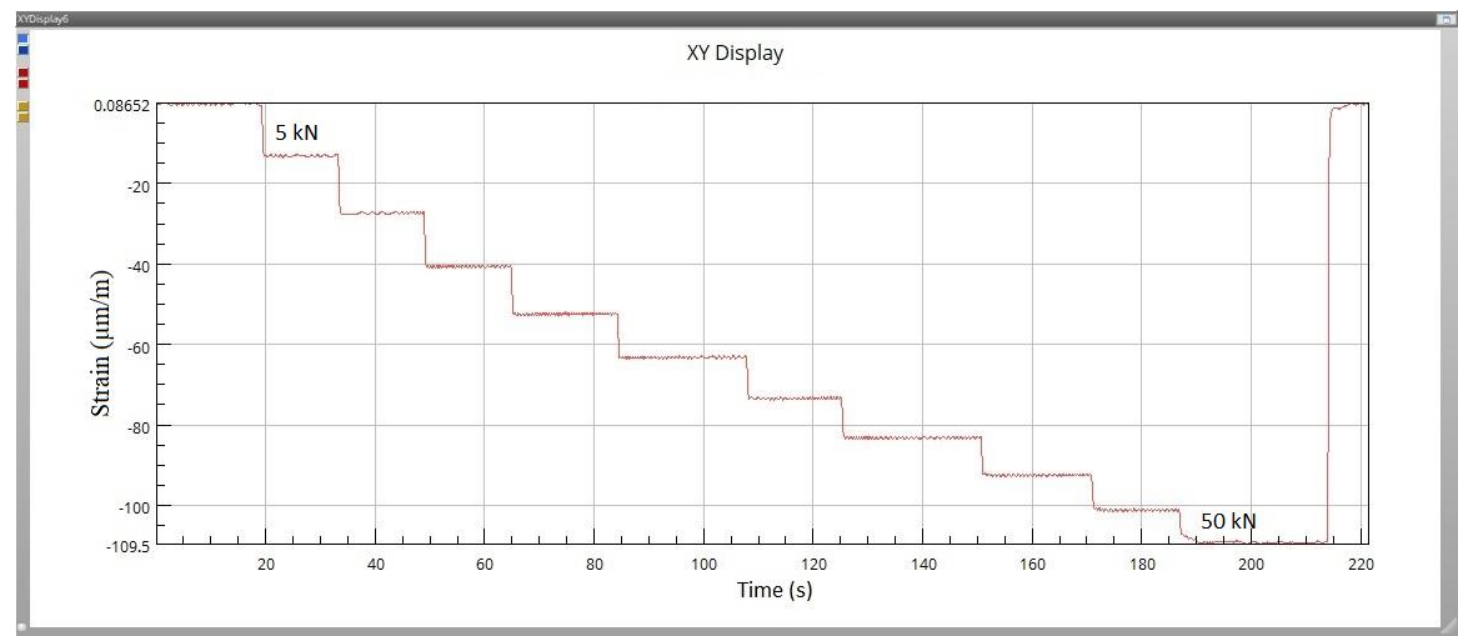

Figure 11. Strain-time graph.

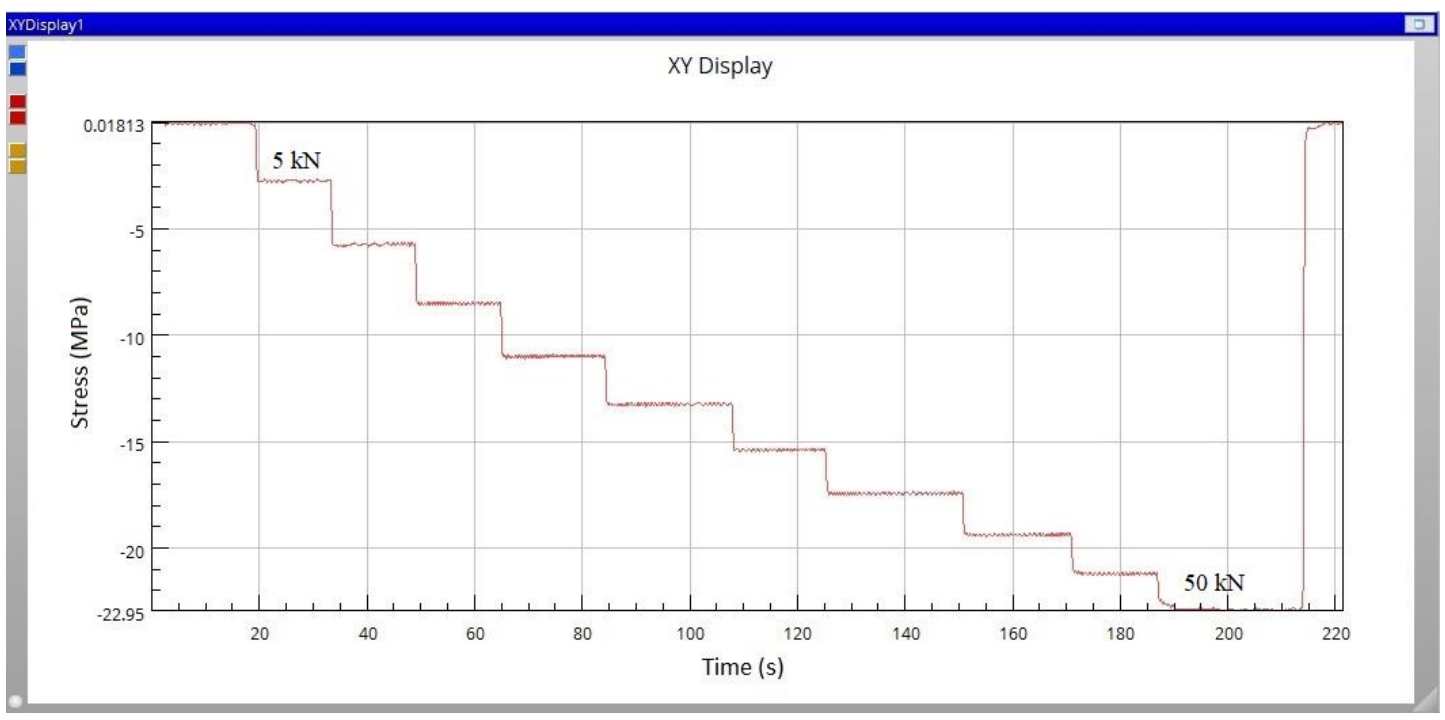

Figure 12. Stres-time graph.

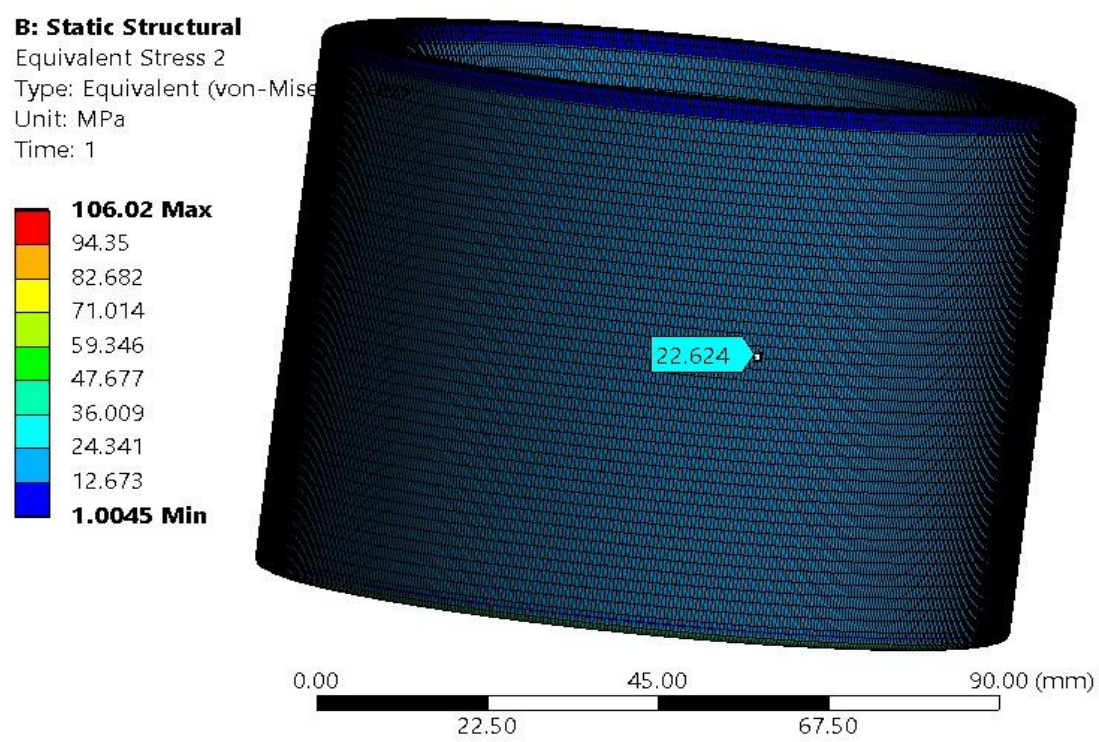

Figure 23. Finite element stress analysis of the application part. 
The fatigue behavior of the systems is calculated by recording the experimental stress measurements under variable loadings. Optimization processes are carried out successfully with these data in aircraft, automobiles, defense industry vehicles and generally construction machines, which are planned to be mass-produced today
[4][19][20][21][22]. In this study, strain and stress data created by variable loadings on the application part were precisely measured and recorded. In the loading simulation seen in Fig. 14, the stress-time graph seen in Fig. 15 was obtained simultaneously.

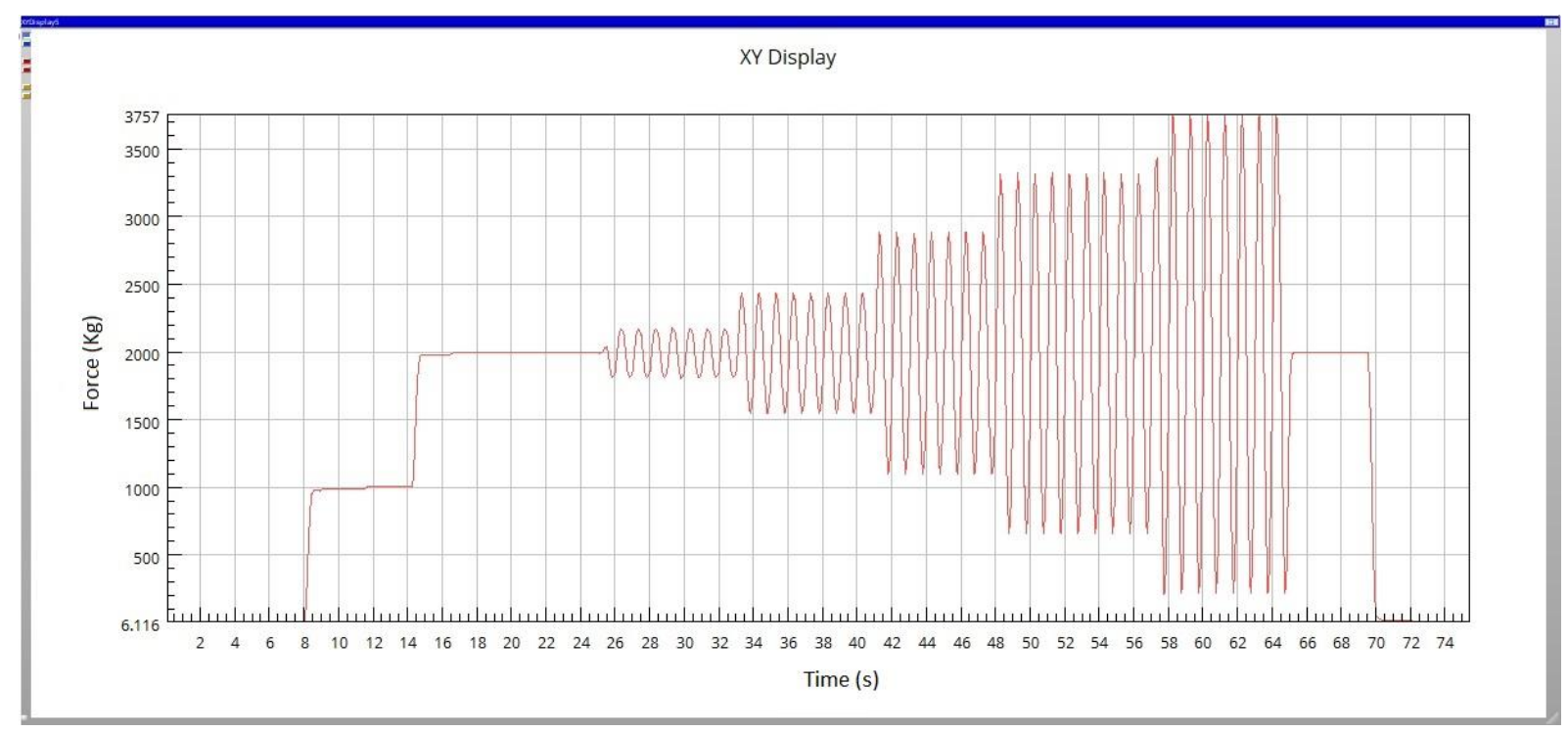

Figure 14. Force-time graph.

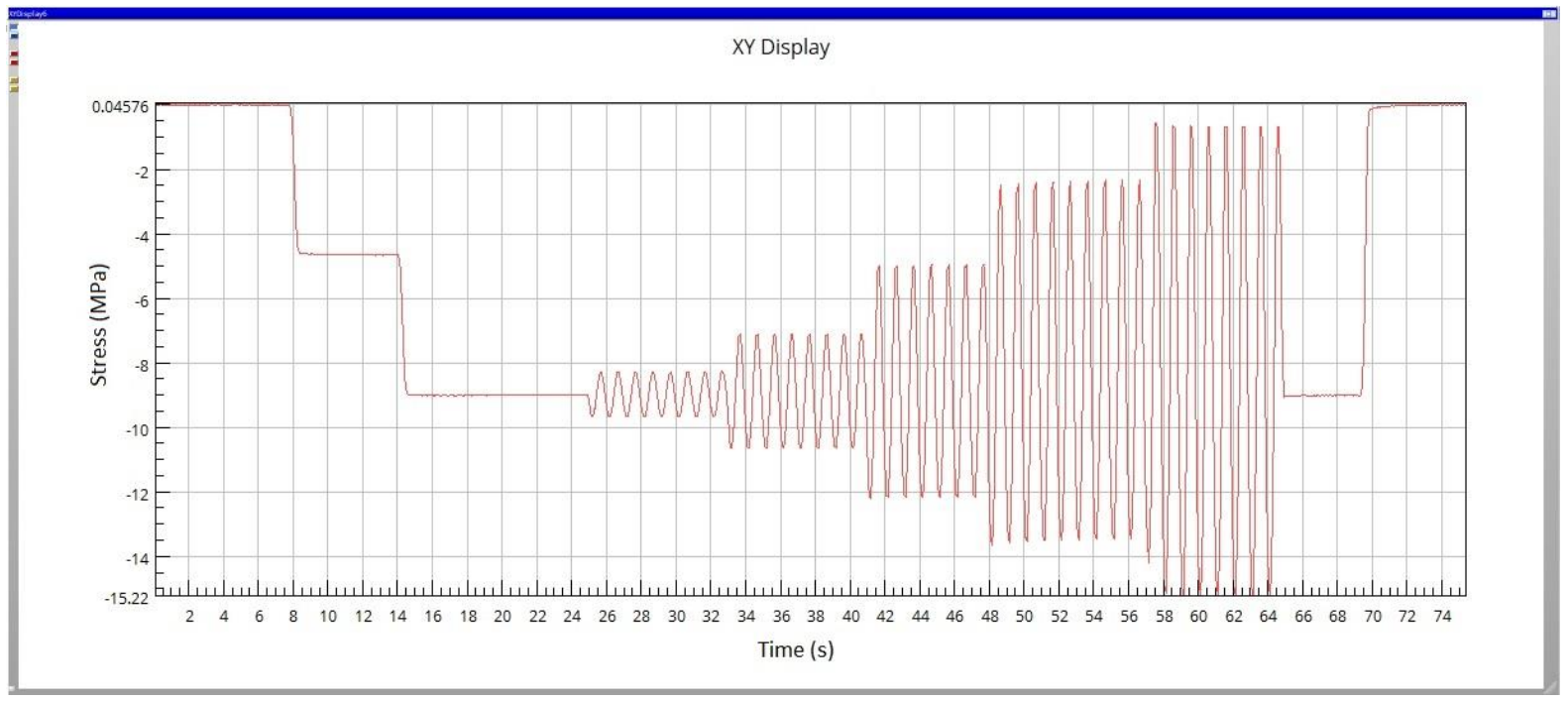

Figure 15. Stress-time graph.

In this study, stress measurement was successfully performed with a wheatstone bridge configuration created with linear gages [23]. Linear gauges have the ability to measure in a single axis. If they are not attached to the force axis on the object, an incorrect measurement is made. If the force axis on an object changes during the operation of the system, then the measurement is made with gages placed at specific angles. It can be preferred in a special rosette where linear gages are brought together [7]. 0/45/90 degree rosette is seen in Fig. 16a. For the data acquisition system connection, 3 quarter bridge wheatstone bridges are required. . This means using the three channels of the data acquisition system. Different size gages can be preferred depending on the application (Fig. 16b). Multi-axis measuring systems can also be created using existing gauges, as shown in Fig. 16c. Strain gage stress 
measurement technology is an effective and efficient method to verify numerical and theoretical solutions and to detect the real stresses directly on the systems during operation [24][25].
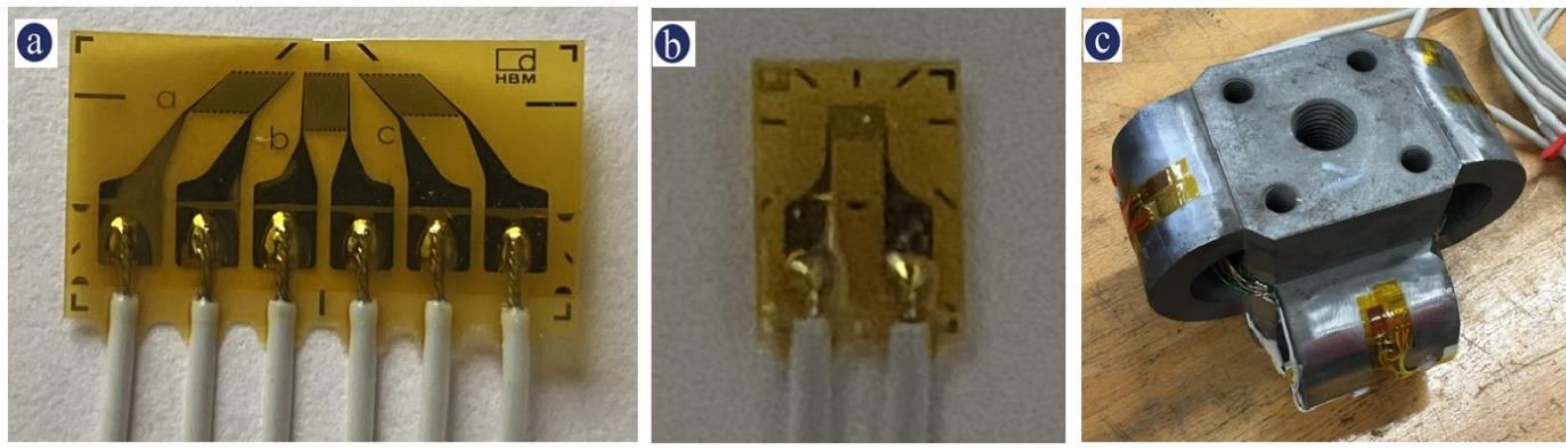

Figure 16. Strain gauge types and applications a) 0/45/90 rosette b) $1.5 \mathrm{~mm}$ grid linear gage c) 6 axis strain measurement application.

\section{Conclusion}

In this study, strain measurement with strain gauge was demonstrated in detail and successfully with an application analytical and numerical results were determined $1.20 \%$ and $1.40 \%$ differed with experimental measurement results, respectively. The full bridge circuit is the optimal configuration for strain gages. It provides the highest precision and measurement with the fewest error components and is less affected by electrical noise. Four active strain gauges, two of them rotated by $90^{\circ}$. The overall effect of the material on the basic strain measurement is compensated due to the poisson's ratio for the full bridge configuration. Normal strain is measured independently of bending strain (bending is excluded), Temperature effects are well compensated, High output signal and excellent common mode rejection.

The most important conclusions drawn from this study can be briefly presented for the use of strain gauge technology as follows:

- The type of material to be measured, its dimensions and the ambient temperature are important in the selection of strain gauges.

- The surface must be cleaned with chemicals and an electrostatic structure must be created.

- Measurements can be made in the elastic region of the material by strain gauges.

- Strain can be measured economically and efficiently with $0.05 \%$ sensitivity in a short time with the help of strain strain gauges.

- Universal data acquisition system (amplifier) can measure both strain gauges and other sensor data (0-10V, 4-20 mA) simultaneously.
- Quarter, half, full bridge configurations should be preferred according to measurement accuracy and application.

- Especially in measuring the strength of prototypes of mass-produced products with strain gauge measurements, it is highly beneficial for systems to be lighter and more durable.

- Continuous measurement can be performed with strain gauge data collection devices for the early detection of damage and accidents in the case of systems operating on ships, airplanes and bridges.

- Strain gauges provide low cost and high efficiency especially in prototype development studies, verification of computer aided finite element solutions, monitoring of the strength of constructions, optimization studies.

\section{Conflict of interest}

There is no conflict of interest with any person / institution in the article prepared

\section{Acknowledgement}

This work was supported by Sensor Tek Eng. and Measurement Systems Industry Ltd. Co. and Matil Material Testing and Innovation Laboratories Co.

\section{References}

[1] K. Hoffmann, "An Introduction to Measurements using Strain Gages," Hottinger Baldwin Messtechnik GmbH, p. 257,1989 .

G. İrsel, "Strength-based design of a fertilizer spreader chassis using computer aided engineering and experimental validation," Proc. Inst. Mech. Eng. Part C J. Mech. Eng. Sci., 2021, doi: $10.1177 / 0954406221993847$. and I. Akinci, "Strength-based design analysis of a ParaPlow tillage tool," Comput. Electron. Agric., vol. 169, 
no. December 2019, p. 105168, 2020, doi: 10.1016/j.compag.2019.105168.

[4] T. J. Lisle, B. A. Shaw, and R. C. Frazer, "Internal spur gear root bending stress: A comparison of ISO 6336:1996, ISO 6336:2006, VDI 2737:2005, AGMA, ANSYS finite element analysis and strain gauge techniques," Proc. Inst. Mech. Eng. Part C J. Mech. Eng. Sci., vol. 233, no. 5, pp. 1713-1720, 2019, doi: $10.1177 / 0954406218774364$.

[5] G. İrsel, "Effects of modification on the strength-weight ratio of standard bevel gears," Mech. Based Des. Struct. Mach., 2021, doi: 10.1080/15397734.2021.1960562.

[6] H. Moustabchir, Z. Azari, S. Hariri, and I. Dmytrakh, "Experimental and numerical study of stress-strain state of pressurised cylindrical shells with external defects," Eng. Fail. Anal., vol. 17, no. 2, pp. 506-514, 2010, doi: 10.1016/j.engfailanal.2009.09.011.

[7] H. Yurdem, A. Degirmencioglu, E. Cakir, and E. Gulsoylu, "Measurement of strains induced on a threebottom moldboard plough under load and comparisons with finite element simulations," Meas. J. Int. Meas. Confed., vol. 136, pp. 594-602, 2019, doi: 10.1016/j.measurement.2019.01.011.

[8] H. K. Celik, A. E. W. Rennie, and I. Akinci, "Design and structural optimisation of a tractor mounted telescopic boom crane," J. Brazilian Soc. Mech. Sci. Eng., vol. 39, no. 3, pp. 909-924, 2017, doi: 10.1007/s40430-0160558-y.

[9] H. Ma, J. Wang, G. Li, and J. Qiu, "Fatigue redesign of failed sub frame using stress measuring, FEA and British Standard 7608," Eng. Fail. Anal., vol. 97, no. January, pp. 103-114, 2019, doi 10.1016/j.engfailanal.2019.01.032.

[10] S. S. Patil, S. Karuppanan, I. Atanasovska, and A. A Wahab, "Contact stress analysis of helical gear pairs, including frictional coefficients," Int. J. Mech. Sci., vol. 85, pp. 205-211, 2014, doi: 10.1016/j.ijmecsci.2014.05.013.

[11] B. Gao, X. Chen, and G. Chen, "Ratchetting and ratchetting boundary study of pressurized straight low carbon steel pipe under reversed bending," Int. J. Press. Vessel. Pip., vol. 83, no. 2, pp. 96-106, 2006, doi: 10.1016/j.ijpvp.2005.12.002.

[12] T. J. Lisle, B. A. Shaw, and R. C. Frazer, "External spur gear root bending stress: A comparison of ISO 6336:2006, AGMA 2101-D04, ANSYS finite element analysis and strain gauge techniques," Mech. Mach. Theory, vol. 111, pp. 1-9, 2017, doi: 10.1016/j.mechmachtheory.2017.01.006.

[13] R. A. B. Almeida, D. C. Vaz, A. P. V. Urgueira, and A. R. Janeiro Borges, "Using ring strain sensors to measure dynamic forces in wind-tunnel testing," Sensors Actuators, A Phys., vol. 185, pp. 44-52, 2012, doi: 10.1016/j.sna.2012.07.024.
[14] Y. Lou, J. Wei, and S. Song, "Design and Optimization of a Joint Torque Sensor for Robot Collision Detection," IEEE Sens. J., vol. 19, no. 16, pp. 6618-6627, 2019, doi: 10.1109/JSEN.2019.2912810.

[15] K. Papadopoulos, "Technique for Measurement of," Wind ENERGY, vol. 3, no. May 1999, pp. 35-65, 2000.

[16] M. Bruner, M. Catena, D. Cortis, G. Malavasi, S. Rossi, and M. Testa, "Estimation of the wheel-rail lateral contact force through the analysis of the rail web bending strains," Meas. J. Int. Meas. Confed., vol. 99, pp. 23-35, 2017, doi: 10.1016/j.measurement.2016.12.015.

[17] D. Corminboeuf, "Calibration of bridge standard for strain gauge bridge amplifier," 17th Int. Congr. Metrol. CIM 2015, vol. 4, pp. 2-6, 2015, doi: 10.1051/metrology/20150004004.

[18] S. I. Gavrilenkov, S. S. Gavriushin, and V. A. Godzikovsky, "Multicriteria approach to design of strain gauge force transducers," J. Phys. Conf. Ser., vol. 1379, no. 1, 2019, doi: 10.1088/1742-6596/1379/1/012010.

[19] S. Bošnjak, Z. Petković, N. Zrnić, G. Simić, and A. Simonović, "Cracks, repair and reconstruction of bucket wheel excavator slewing platform," Eng. Fail. Anal., vol. 16, no. 5, pp. 1631-1642, 2009, doi: 10.1016/j.engfailanal.2008.11.009.

[20] H. K. Y. T. K. Sasaki, "Four-Point Bending Test of Determining Stress-Strain Curves Asymmetric between Tension and Compression," pp. 489-492, 2014, doi: 10.1007/s11340-013-9791-9.

[21] A. M. Abou-Rayan, N. N. Khalil, and A. A. Zaky, "Experimental investigation on the flexural behavior of steel cold-formed I-beam with strengthened hollow tubular flanges," Thin-Walled Struct., vol. 155, no. July, p. 106971, 2020, doi: 10.1016/j.tws.2020.106971.

[22] J. Ye, I. Hajirasouliha, and J. Becque, "Experimental investigation of local-flexural interactive buckling of cold-formed steel channel columns," Thin-Walled Struct., vol. 125, no. July 2017, pp. 245-258, 2018, doi: 10.1016/j.tws.2018.01.020.

[23] L. D. V. Anand, D. Hepsiba, S. Palaniappan, B. Sumathy, P. Vijayakumar, and S. S. Rani, "Automatic strain sensing measurement on steel beam using strain gauge," Mater. Today Proc., vol. 45, pp. 2578-2580, 2021, doi: 10.1016/j.matpr.2020.11.274.

[24] V. Goga, "Finite Element Model of the Strain Gauge for Determining 1 Introduction 2 Principle of the Strain Gauge Measurement," Trans. V̌̌B - Tech. Univ. Ostrava, Mech. Ser. No., vol. LIX, no. 2, pp. 67-73, 2013. 